\title{
RESÍDUOS DE ANTIMICROBIANOS EM LEITE BOVINO CRU NO ESTADO DO RIO GRANDE DO NORTE
}

\section{ANTIMICROBIAL RESIDUES IN BOVINE MILK IN NATURA IN RIO GRANDE DO NORTE}

\author{
Lara Barbosa de Souza ${ }^{1}$ \\ Carolina de Gouveia Mendes da Escóssia Pinheiro ${ }^{1}$ \\ Severino Antonio Geraldo Neto ${ }^{1}$ \\ Jean Berg Alves da Silva ${ }^{1^{*}}$ \\ 1 Universidade Federal Rural do Semi-Árido, Mossoró, RN, Brasil. \\ *Autor para correspondência - jeanberg@ufersa.edu.br
}

\section{Resumo}

O descumprimento do período de carência dos medicamentos aplicados em vacas leiteiras leva à presença de substâncias químicas em limites inadequados no leite. Com o intuito de avaliar a presença de resíduos de antimicrobianos no leite bovino cru produzido no Rio Grande do Norte (RN), foram coletadas 112 amostras de leite cru oriundas de seis municípios do Estado do RN. A pesquisa de resíduos foi realizada com o uso do kit ECLIPSE $50^{\circledR}$. Foi observado que seis $(6,72 \%)$ amostras apresentaram resultado positivo para detecção de resíduos. Desta forma, o leite comercializado no Estado pode gerar riscos à saúde da população consumidora.

Palavras-chave: qualidade; antibióticos; saúde pública.

\begin{abstract}
The noncompliance the grace period of the medicines used in cows in lactation stage or dry leads to the presence of chemicals inadequate on the milk. In order to evaluate the presence of antimicrobial residues in raw milk produced in Rio Grande do Norte (RN), were collected 112 samples of raw milk from six municipalities in the State of the RN. The residue testing was performed using the ECLIPSE $50{ }^{\circledR}$ kit. It was observed that six $(6.72 \%)$ samples were positive for detection of residues. Thus, the milk sold in the state can generate risks to the health of the consumer population.
\end{abstract}

Keywords: quality; antibiotics; public health.

Recebido em: 12 de março de 2013

Aceito em: 21 de agosto de 2017

\section{Introdução}

A qualidade do leite é avaliada pelas suas características sensoriais, físico-químicas, ausência de 
micro-organismos patogênicos, de conservantes químicos e resíduos de antibióticos ${ }^{(1,2)}$.

Os agentes mais relacionados a enfermidades veiculadas por alimentos são os micro-organismos, mas a presença de resíduos de substâncias químicas é comum em todo o mundo. Resíduos de antimicrobianos são detectados com alta frequência e a presença destes resíduos no leite é considerada uma contaminação e/ou adulteração do produto $^{(3)}$. A ocorrência de antimicrobianos no leite deriva do tratamento de vacas em lactação que apresentam doença infecciosa, ou devido ao controle de mastite durante o período $\operatorname{seco}^{(4)}$.

Essas substâncias são eliminadas pelo leite durante seu período de carência, sendo a persistência do resíduo variável, de acordo com o antibiótico e depende de vários fatores como dose e via de administração ${ }^{(5,6)}$. Quando presentes no alimento, podem causar efeitos tóxicos diretos sobre os consumidores, como reações alérgicas e choque anafilático, ou ainda problemas de resistência microbiana e efeitos colaterais secundários ${ }^{(7)}$. Na indústria, a principal consequência é a interferência na produção dos derivados lácteos, prejudicando o processo de fermentação e elaboração de queijos, iogurte e leites fermentados, ocasionando perda de rendimento e modificação na qualidade do produto final ${ }^{(8)}$.

A Instrução Normativa n ${ }^{\circ} 62$ de 2011 do Ministério da Agricultura Pecuária e Abastecimento (MAPA) indica a pesquisa periódica com relação à presença de antibióticos no leite, a qual deve obedecer aos Limites Máximos de Resíduos (LMRs) previstos para cada grupo químico específico ${ }^{(9)}$.

Diversos kits de detecção de resíduos de antibióticos estão disponíveis no mercado, porém baseados em diferentes métodos: testes de inibição do crescimento bacteriano, testes imunológicos, testes físico-químicos e testes que usam receptores e enzimas ${ }^{(10)}$.

Os testes de inibição do crescimento microbiano são comumente utilizados devido ao baixo custo e fácil execução ${ }^{(11)}$. Um exemplo deles é o Eclipse 50, que contém um meio de cultivo específico com esporos de Geobacillus stearothermophilus, no qual após a incubação da amostra de leite na placa, caso os esporos microbianos germinem e acidifiquem o meio, ocorre modificação de cor. Se a concentração de antibiótico na amostra for maior que o limite de detecção do teste, inibe o microorganismo, e a cor do meio permanece inalterada, possibilitando verificar se o leite contém antibióticos em uma concentração acima do LMR.

Considerando a importância do leite bovino na alimentação humana, além dos riscos à saúde da população e os prejuízos na indústria de laticínios que a presença de resíduos de antimicrobianos representa, o objetivo do trabalho foi pesquisar resíduos antimicrobianos no leite bovino cru produzido no Rio Grande do Norte.

\section{Material e Métodos}

Foram analisadas 112 amostras de leite bovino cru, no mês de novembro de 2012, oriundas de produtores de seis municípios de diferentes mesorregiões do Estado do Rio Grande do Norte, sendo: Angicos (60), Afonso Bezerra (4), Fernando Pedroza (5), Itajá (1), Mossoró (4) e Santana dos Matos (38). Cada amostra foi coletada de forma aleatória, no momento da entrega do leite em uma usina de 
beneficiamento, com cada uma representando um produtor.

As amostras analisadas eram destinadas a uma usina de beneficiamento de leite pasteurizado com SIE (Serviço de Inspeção Estadual). Estas eram transportadas em caixa térmica até o Laboratório de Inspeção de Produtos de Origem Animal - LIPOA, localizado na Universidade Federal Rural do Semi-Árido - UFERSA, onde foram submetidas à detecção de resíduo de antimicrobianos, com o kit ECLIPSE $50^{\circledR}$.

Para evitar resultados falso positivos pela presença de inibidores naturais, as amostras foram submetidas à tratamento térmico (banho-maria) de $80^{\circ} \mathrm{C}$ por dez minutos. Em seguida, uma alíquota de $50 \mathrm{uL}$ da amostra foi adicionada ao poço do teste. A microplaca contendo as amostras ficou em banho-maria sob temperatura de $65^{\circ} \mathrm{C}$ por 2 horas e 15 minutos. Foi utilizado como controle positivo leite sabidamente contaminado com estreptomicina. As amostras foram consideradas positivas quando não havia mudança colorimétrica, permanecendo inalterada a cor dos poços da microplaca. Os limites de detecção do kit estão representados na Tabela 1.

Tabela 1. Limites de detecção $(\mu \mathrm{G} / \mathrm{ML})$ de antibióticos do kit Eclipse $50^{8}$

\begin{tabular}{ccc}
\hline Eclipse 50 & Negativo & Positivo \\
\hline Penicilina G & 0,002 & 0,004 \\
Ampicilina & 0,003 & 0,005 \\
Amoxicilina & 0,003 & 0,005 \\
Oxacilina & $\leq 0,005$ & 0,025 \\
Cloxacilina & 0,025 & 0,04 \\
Cefalexina & 0,025 & 0,075 \\
Cefapirina & 0,005 & 0,008 \\
Sulfatiazol & 0,02 & 0,075 \\
Sulfametacina & 0,1 & 0,2 \\
Sulfanilamida & 0,1 & 0,6 \\
Oxitetraciclina & 0,05 & 0,15 \\
Tetraciclina & 0,05 & 0,15 \\
Eritromicina & 0,2 & 0,4 \\
Tilosina & 0,02 & 0,1 \\
Neomicina & $<0,5$ & 0,8 \\
Estreptomicina & 2 & 3 \\
\hline
\end{tabular}

\section{Resultados e Discussão}

Das 112 amostras analisadas, seis $(6,72 \%)$ apresentaram resultado positivo para resíduos de antimicrobianos (Tabela 2). 
Tabela 2. Resíduos de antimicrobianos em amostras de leite bovino cru em municípios do estado do Rio Grande do Norte

\begin{tabular}{ccc}
\hline Municipios & Amostras avaliadas & $\begin{array}{c}\text { Amostras com resíduos } \\
\text { de antimicrobiano }\end{array}$ \\
\hline Angicos & 60 & $1(0,6 \%)$ \\
Afonso Bezerra & 4 & 0 \\
Fernando Pedroza & 5 & 0 \\
Itajá & 1 & 0 \\
Mossoró & 4 & $3(75 \%)$ \\
Santana dos Matos & 38 & $2(0,8 \%)$ \\
Total & 112 & $6(6,72 \%)$ \\
\hline
\end{tabular}

O aparecimento de resíduos de antibióticos no leite deriva comumente do tratamento de doenças do animal. Portanto, a presença destes resíduos no leite é proveniente de tratamentos terapêuticos. Do antibiótico aplicado na glândula mamária, cerca de 30 a $80 \%$ passa da corrente sanguínea para o leite ${ }^{(2)}$. Em trabalhos que utilizaram o mesmo kit de detecção, ECLIPSE $50^{\circledR}$, os resultados foram diferentes do presente trabalho. Sousa et al. ${ }^{(12)}$, ao avaliarem o leite pasteurizado da região caririense, constataram a presença de resíduo antimicrobiano em 4 (13,33\%) amostras. Já Robim et al. ${ }^{(13)}$ analisaram 58 amostras de leite UAT (Ultra Alta Temperatura) de diferentes marcas comercializadas no estado do Rio de Janeiro e não detectaram resultados positivos.

Sousa et al. ${ }^{(14)}$, ao avaliarem a ocorrência de resíduos de antibióticos em 30 amostras de leite pasteurizado comercializados no Ceará, observaram a presença destes resíduos em 23 (76,67\%) das amostras analisadas.

Outros autores pesquisaram resíduo de antimicrobiano no leite utilizando kits de detecção diferentes, porém com o mesmo princípio do aplicado neste trabalho, apresentaram divergências de resultados. Nero et al. ${ }^{(15)}$, ao analisarem amostras de leite cru oriundas de quatro regiões leiteiras do Brasil, detectaram a presença de resíduos em 24 (11,43\%) amostras das 210 analisadas.

De acordo com Martins \& Andrade ${ }^{(16)}$, as análises para detecção de resíduos antimicrobianos em leite tornaram-se rotineiras, facilitando o acesso aos kits de detecção e caracterizando esta etapa como Ponto de Controle (PC) no programa de pré-requisitos das indústrias, já que afeta diretamente a qualidade do produto e a segurança do consumidor.

O leite contendo resíduos antimicrobianos acima do permitido pela legislação é considerado adulterado e impróprio para o consumo humano ${ }^{(17)}$. A presença deste resíduo no leite poderá ocasionar vários efeitos indesejáveis no ambiente e no consumidor, como a seleção de cepas bacterianas resistentes, hipersensibilidade e possível choque anafilático em indivíduos alérgicos; desequilíbrio da flora intestinal e efeito teratogênico. Pode também inibir o metabolismo dos microorganismos fermentadores, interferindo nos caracteres organolépticos e tecnológicos dos produtos lácteos industrializados, principalmente no processamento tecnológico do iogurte, manteiga e queijo, gerando prejuízos à indústria na manufatura dos produtos lácteos ${ }^{(18-20)}$. 


\section{Conclusão}

O leite bovino cru oriundo de propriedades rurais do Rio Grande do Norte apresentou contaminação com resíduos de antibióticos. Apesar da baixa positividade encontrada, a presença de resíduos de antibióticos no leite bovino cru deve ser um motivo de preocupação para autoridades sanitárias e laticínios, pelo risco que pode causar à saúde do consumidor e os prejuízos na produção de derivados lácteos, respectivamente.

\section{Agradecimentos}

Ao Banco do Nordeste pelo apoio financeiro para a realização deste trabalho.

\section{Referências}

1. Santos AFR, Rodrigues MAM. Resíduos inibidores em leite UHT. Higiene Alimentar. 2003;17(104):174175.

2. Tronco VM. Manual para Inspeção da Qualidade do Leite. $4^{\mathrm{a}}$ ed. Santa Maria: Editora UFSM; 2010.

3. Silva MVM, Sarmento AMC, França AP. Resíduos de antibióticos no leite e seus efeitos na saúde pública: uma preocupação constante. Anais do $35^{\circ}$ Congresso Brasileiro de Medicina Veterinária; 19-22 Out 2008, Gramado, RS, Brasil. Gramado: COMBRAVET; 2008, CDRom.

4. Brito MAVP. Resíduos de antimicrobianos no leite. Juiz de Fora: Embrapa Gado de Leite, 2000. 28p. Circular Técnica, 60.

5. Nascimento GGF, Maestro V, Campos MSP. Ocorrência de resíduos de antibióticos no leite comercializado em Piracicaba, SP. Revista de Nutrição. 2001;14(2):119-124.

6. Costa EO. Resíduos de antibióticos no leite: um risco à saúde do consumidor. Higiene Alimentar. 1996;10(44):15-17.

7. Tetzner TAD, Benedetti E, Guimarães EC, Peres RFG. Prevalência de resíduos de antibióticos em amostras de leite cru na região do Triângulo Mineiro, MG. Higiene Alimentar. 2005;19(130):69-72.

8. Dietrich JM. Controle de Resíduo de antibióticos no leite. Leite \& Derivados. 2008;106:156-162.

9. Brasil. Ministério da Agricultura, Pecuária e Abastecimento - MAPA. Instrução Normativa ${ }^{\circ} 62$, de 22 de dezembro de 2011 [acesso 20 Jul 2017]. Disponível em http://www.apcbrh.com.br/files/IN62.pdf

10. Guedes CC, Matos CM, Moutinho CG, Silva CS. Avaliação de utilização da espectrofotometria de UV/VIS na quantificação de antibióticos em extractos de leite de vaca. Revista da Faculdade de Ciências da Saúde. 2009;6:232-243.

11. Battes NM, Selevan GS, Ellerber MS, Gartner ML. Reporting needs for studies of environmental chemicals in human milk. Journal of Toxicology and Environmental Health, Part A. 2002;65(22)1867-1879.

12. Sousa FC, Silva LMM, Silva JN, Cruz CSA, Sousa EP. Resíduos de antibiótico em amostras de leite pasteurizado tipo c comercializado na região caririense. Revista Verde de Agroecologia e Desenvolvimento 
Sustentável. 2012;7(2):21-24.

13. Robim MS, Cortez MAS, Silva ACO, Torres Filho RA, Gemal NH, Nogueira EB. Pesquisa de fraude no leite UAT integral comercializado no estado do Rio de Janeiro e comparação entre os métodos de análises físico-químicas oficiais e o método de ultrassom. Revista do Instituto de Laticínios Cândido Tostes. 2012;67(389):43-50.

14. Sousa FC, Oliveira ENA, Santos DC, Silva EFM. Ocorrência de resíduos de antibióticos em leites pasteurizados comercializados no Estado do Ceará-Brasil. Revista Verde de Agroecologia e Desenvolvimento Sustentável. 2010;5(4):10-14.

15. Nero LA, Mattos MR, Berloti V, Barros MAF, Franco BDGM. Resíduos de antibióticos em leite cru de quatro regiões leiteiras no Brasil. Ciência e Tecnologia de Alimentos 2007;27(2):391-393.

16. Martins PF, Andrade HV. Identificação de resíduos de antibióticos na recepção de leite cru pré-beneficiado como perigo potencial para implantação do plano APCC em laticínios. Revista FAZU. 2011;2:108-114.

17. Gomes MF. Avaliação da eficiência de "kits" destinados à detecção de resíduo de antimicrobianos em leite de vacas tratadas com ivermectina e abamectina [Dissertação de Mestrado]. Belo Horizonte: Universidade Federal de Minas Gerais; 2005 [acesso 20 Jul 2017]. Disponível em: http://hdl.handle.net/1843/SSLA7TYN8T

18. Biacchi NC, Jorge AOC, Ueno M. Deteç̧ão de resíduos de antibióticos em leite bovino na região do Vale do Paraíba, São Paulo. Revista Biociência. 2004;10(1-2):47-9.

19. Costa EO. Uso de antimicrobianos na mastite. In: Spinosa HS, Górniak SL, Bernardi MM. Farmacologia Aplicada à Medicina Veterinária. $4^{\mathrm{a}}$ ed. Rio de Janeiro: Guanabara Koogan; 2006. p. 501-515.

20. Silva RM, Silva RC, Ribeiro AB. Resíduos de antibióticos em leite. SaBios: Revista Saúde e Biologia. 2012;7(1):30-44. 